\title{
Anatomical variation of bony pelvis from the viewpoint of transobturator sling placement for stress urinary incontinence
}

\author{
Michał Bogusiewicz • \\ Katarzyna Rosińska-Bogusiewicz • Andrzej Drop • \\ Tomasz Rechberger
}

Received: 23 December 2010 / Accepted: 22 March 2011 /Published online: 12 April 2011

(C) The Author(s) 2011. This article is published with open access at Springerlink.com

\begin{abstract}
Introduction and hypothesis The aim of the study was to investigate the variability of bony pelvis architecture from the viewpoint of transobturator sling placement.

Methods The pelvimetry was performed on 122 women who underwent pelvic computed tomography. Measurements included: the distance between the interobturator foramina line and inferior pubic symphysis (IF-PS distance) as well as pubic arch angle, pubic ramus width, and pubic symphysis length.

Results The length of the IF-PS distance varied between 7.4 and $26.9 \mathrm{~mm}$ (mean $15.2 \pm 4.3 \mathrm{~mm}$, median $14.2 \mathrm{~mm}$ ). The distribution of measurements was asymmetrical with a tilt of the values towards shorter distances. In $11.5 \%$ of women, the IF-PS distance was longer than $20 \mathrm{~mm}$. The IF-PS distance correlated with the pubic ramus width $(r=0.37$, $p<0.0001)$ and pubic arch angle $(r=-0.22, p=0.017)$.

Conclusion The IF-PS distance varies considerably in the general population of women.
\end{abstract}

Keyword Bony pelvis $\cdot$ Suburethral sling $\cdot$ Urinary incontinence Computed tomography

M. Bogusiewicz, K. Rosińska-Bogusiewicz, A. Drop, and T. Rechberger contributed to the manuscript.

M. Bogusiewicz $(\bowtie) \cdot$ T. Rechberger

Second Department of Gynaecology,

Medical University of Lublin,

Jaczewskiego 8,

20-090 Lublin, Poland

e-mail: mbogusiewicz@yahoo.com

K. Rosińska-Bogusiewicz • A. Drop

Department of Medical Radiology of Lublin,

Medical University of Lublin,

Lublin, Poland

\section{Introduction}

Suburethral slings, due to high effectiveness and safety, are currently the mainstay of therapy for female stress urinary incontinence (SUI). The rate of failure ranges from $5 \%$ to $15 \%$ and is related to aging, intrinsic sphincter deficiency, previous anti-incontinence surgery, concurrent prolapse, and mixed urinary incontinence [1-4]. Recent ultrasound studies showed that unsuccessful outcome in most of the cases is secondary to improper tape position. After the transobturator tape (TVT) procedure location of a tape under the urethra between the 50th to 80th percentile of the urethral length (measured from the bladder neck) results in the favorable outcome in $91 \%$ patients, whereas position outside this section is associated with failure in $36 \%$ of patients [5]. Correspondingly, Yung et al. [6] showed that position of a TVT obturator under the proximal half of the urethra increases the failure risk sixfold. Among patients with recurrent SUI after midurethral slings managed at our department more than $70 \%$ had tapes under the proximal part of the urethra (unpublished). Thus, location of a tape to close to the bladder neck may be a critical factor for sling failure.

There is no unequivocal explanation of the reasons of improper tape position. It is obvious that it may result from incorrect surgical technique. However, in a subset of patients, anatomical conditions, especially the bony pelvis architecture, may also play a pivotal role. It may be hypothesized then that in some women, due to their bony pelvis anatomy, proper placement of a tape may be impossible, despite applying ideal surgical technique.

The aim of the study was to investigate the variability of bony pelvis architecture from the viewpoint of transobturator sling placement using computed tomography scanning. 


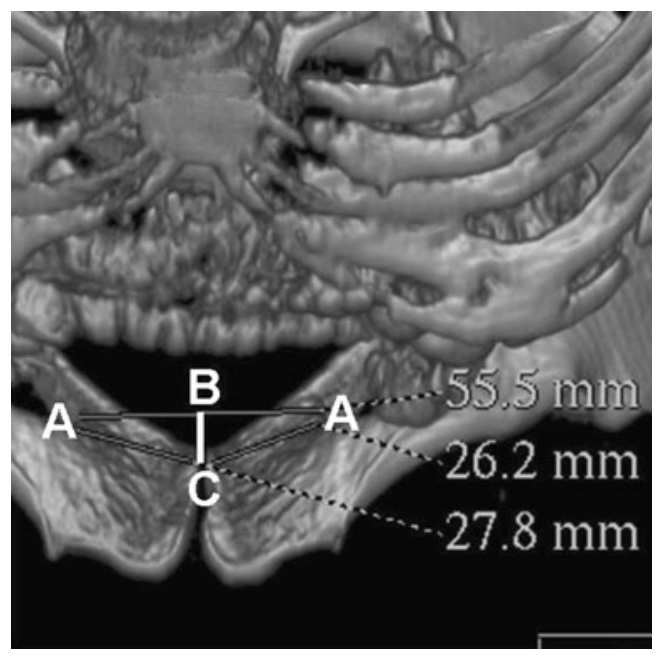

Fig. 1 Measurements done for the calculation of the distance between the interobturator foramina line and inferior pubic symphysis $(B-C)$ : the interobturator foramina distance between the medial margins of the obturator foramina $(A-A)$ and the pubic symphysis-obturator foramina margin distance $(A-C)$ between the pubic symphysis and the medial margins of the obturator foramina. The mean value of the latter distance was used for calculations

\section{Materials and methods}

The pelvimetry was performed on 122 Caucasian women aged from 21 to 81 (mean 55.9 \pm 13.4 )years, who underwent pelvic computed tomography in the Department of Medical Radiology, Medical University of Lublin. Indications for the examination were clinical such as pelvic and abdominal masses, abdominal pain and abdominal inflammatory processes. Women with pelvic bone trauma or previous pelvic or

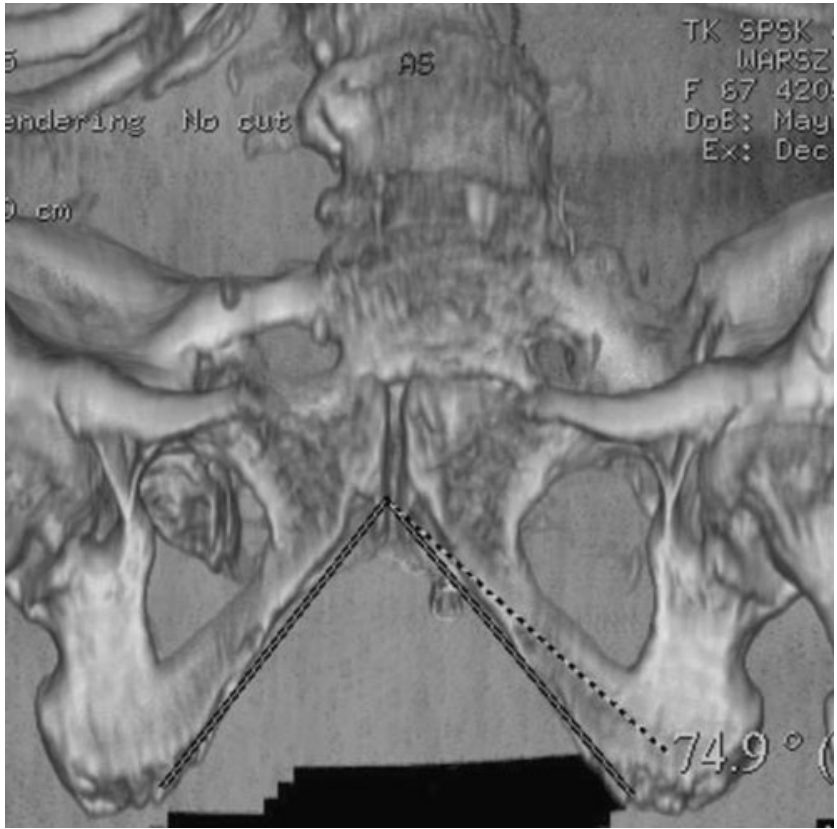

Fig. 2 Measurement of the pubic arch angle

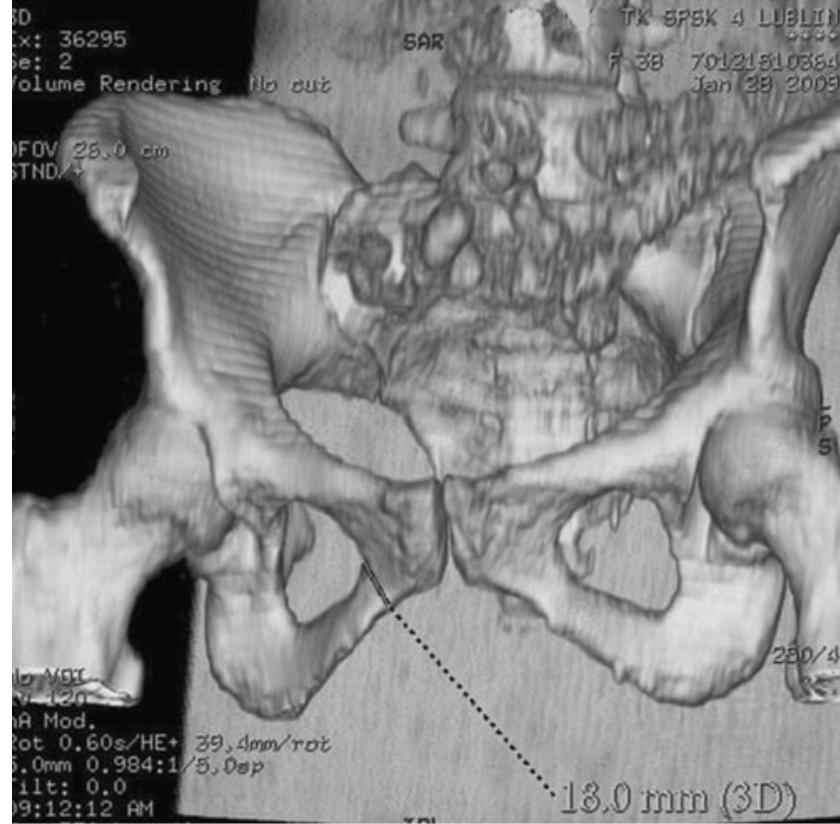

Fig. 3 Measurement of the pubic ramus thickness

hip bone surgery were not included. Pelvic CT examinations were obtained on 64-slice CT scanner (GE Medical System Light Speed VCT) with scanning parameters established at $120-140 \mathrm{kV}, 600-700 \mathrm{mAs}$ with slice thickness at $1.25 \mathrm{~mm}$. The image data were stored in the hospital's picture archiving and communication system archive and retrospectively used for pelvimetry.

The images were reconstructed and pelvimetry was performed by two independent radiologists (KR-B. and

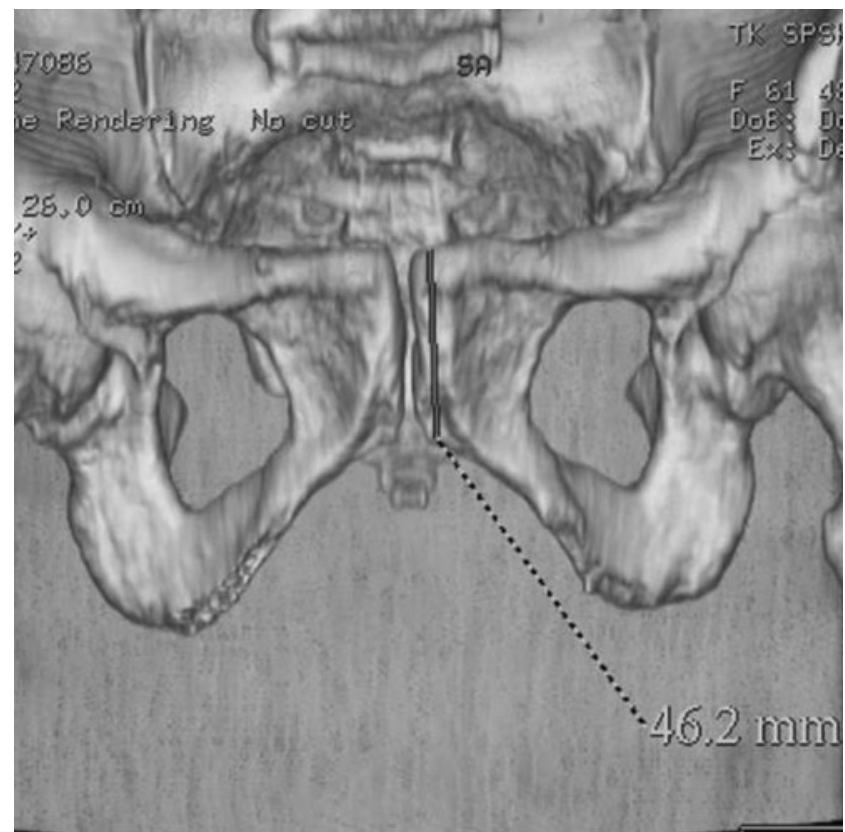

Fig. 4 Measurement of the pubic symphysis length 
Table 1 Variations in the bony pelvic measurements

\begin{tabular}{|c|c|c|c|c|c|c|}
\hline & Mean \pm SD & Median & Minimum & Maximum & Coefficient of variation $(\%)^{\mathrm{a}}$ & Figure \\
\hline $\begin{array}{l}\text { Interobturator foramina line-inferior pubic } \\
\text { symphysis distance }(\mathrm{mm})\end{array}$ & $15.2 \pm 4.3$ & 14.2 & 7.4 & 26.9 & 28.7 & Fig. 1 \\
\hline Interobturator foramina distance $(\mathrm{mm})$ & $56.5 \pm 6.3$ & 56.0 & 37.2 & 74.1 & 11.2 & Fig. 1 \\
\hline Pubic arch angle (deg) & $85.7 \pm 11.9$ & 84.6 & 57.3 & 119.1 & 13.9 & Fig. 2 \\
\hline Pubic ramus width (mm) & $18.0 \pm 3.3$ & 17.8 & 10.6 & 26.5 & 18.5 & Fig. 3 \\
\hline Pubic symphysis length (mm) & $35.5 \pm 4.9$ & 35.0 & 26.4 & 52.3 & 13.7 & Fig. 4 \\
\hline
\end{tabular}

${ }^{\text {a }}$ Coefficient of variation calculated as a ratio of SD to the mean

AD) on a 3D workstation (Advantage Window Workstation 4.0, GE Medical System) using topograms, multiplanar reconstructions, and volume-rendered images. The assessment of interobserver and intraobserver reliability demonstrated good reproducibility.

The study was approved by the institutional review board.

Regarding the anatomical path taken by the transobturator tape, the length of the distance between the interobturator foramina line and inferior pubic symphysis (IF-PS distance) seems to be crucial for tape position under the urethra. The IF-PS distance was calculated using the Pythagorean theorem on the basis of the measurements of the interobturator foramina distance and pubic symphysisobtorator foramina margin distance (Fig. 1). The measurement were done as follows: 3-D volume-rendered images of the bony pelvis were tilted on the transverse plane until the most medial part of the obturator foramen borders were seen, which enables the shortest distance between them as well as between them and the pubic symphysis to be measured.

Other measurements obtained were: the pubic arch angle (Fig. 2), pubic ramus width (Fig. 3) and pubic symphysis length (Fig. 4).

Data were analyzed using Statsoft Statistical version 8 software (Statsoft Inc,. Tulsa, OK, USA). Shapiro-Wilk testing and Lilliefors testing were used for normality. The relationships between IF-PS distance and other measurements were tested through a Spearman correlation coefficient. Statistical significance was set at a $P$ value of less than 0.05 .

To compare the degree of variation within a data set, the coefficient of variation was calculated as a ratio of standard deviation to the mean.

\section{Results}

Results of the bony pelvic measurements are presented in Table 1. Distribution of interobturator foramina line-pubic symphysis distances was asymmetrical and skewed towards shorter values (Fig. 5). Distribution of other variables was normal. Moderate, but statistically significant, correlations between the interobturator foramina line-inferior pubic symphysis distance and pubic ramus width $(r=0.37, p<0.0001)$ as well as pubic arch angle ( $r=-0.22, p=0.017)$ were observed. Shapiro-Wilk testing confirmed non-normality.

\section{Discussion}

Basing on the Integral Theory of stress urinary incontinence described by Petros and Ulmsten [7], placement of a tape precisely under the middle section of the urethra is essential for restoring continence. Some studies showed that location of a tape outside this zone is associated with higher rate of treatment failure; however, the relationship between tape

\section{Histogram for the distance between the interobturator foramina line and inferior pubic symphysis}

No of cases

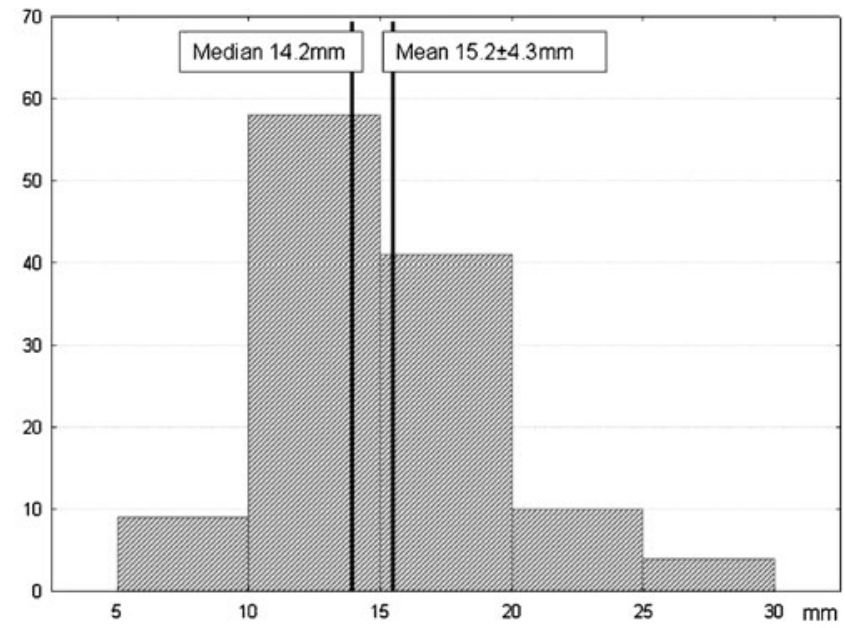

Fig. 5 Distribution of interobturator foramina line-pubic symphysis distances. The distribution is asymmetrical as proved by Shapiro-Wilk and Lilliefors testing (Shapiro-Wilk $W=0.94756, p=0.00013$; Lilliefors $p<0.01)$ 
position and sling result is not unequivocal. In the study reported by $\mathrm{Ng}$ et al. [8], most of the cured patients had TVT located under the midurethra, but in $9.7 \%$ it lay in the proximal one third and $22.6 \%$ in the distal one third of the urethra. Furthermore, Dietz et al. [9] showed that there is no association between tape position and subjective cure rate after TVT procedure. It is assumed that a TVT located outside the midurethra may still serve as a fulcrum upon which the urethra angulates or work as a traditional pubovaginal sling by suspending the bladder neck and proximal urethra [10]. It is unknown whether these mechanisms may be also relevant for transobturator sling.

The position of a tape after transobturator procedure depends on many factors associated with surgical technique, such as localization of vaginal incision and skin exit points, angle of trocar placement as well as pelvic floor anatomy, for instance a degree of prolapse. In this study, we intended to check if there is a variability of bony pelvic anatomy, which may potentially influence the position of the transobturator sling.

The highest degree of variability, as indicated by the coefficient of variation, was observed for the interobturator foramina line-pubic symphysis distance. Its values ranged from 7.4 up to $26.9 \mathrm{~mm}$ and distribution of measurements was asymmetrical with a tilt of the values towards shorter distances. Thus, it may be expected that in most women undergoing transobturator slings anatomy of the bony pelvis is unlikely to influence tape position. However, in $11.5 \%$ of investigated women this distance was longer than $20 \mathrm{~mm}$. Results of ultrasound measurements demonstrated that the mean distance between the bladder neck and symphysis pubis in stress incontinent patients is shorter than $19 \mathrm{~mm}$ [11]. Although the position of the bladder in the patient from our study is unknown, supposedly, a subset of women may be at risk to have tapes placed in the proximity of bladder neck, because of pelvis anatomy. This location of a tape not only increases the risk for unfavorable outcome, but may also lead to the development of postoperative de novo urgency [12].

Not much is known whether the pelvic bone architecture differs in women with urinary incontinence from those in general population. Handa et al. [13] observed that women with urinary incontinence have slightly wider intertuberous diameter and the pelvic arch. Furthermore, it has been shown that boarder pelvic inlet and outlet dimensions are independent risk factors for urinary incontinence [14]. Presumably, a larger pelvic floor area makes the pelvic floor muscles, fascias, and ligaments more prone to weakening and stretching that result in higher incidence of incontinence. In our population, the length of the IF-PS distance was inversely related the pubic arch angle. Although this relationship was weak, it seems reasonable to assume that the IF-PS distance is longer in women with narrower pelvises. On the other hand, it is unlikely that measurement of the pubic arch angle may facilitate identification of women with longer the IF-PS distances.

Interestingly, the IF-PS distance was moderately related to the width of the pubic ramus. The pubic ramus width varied between 10.6 and $26.5 \mathrm{~mm}$ with coefficient of variation $18.5 \%$. Although it may be palpated during the transobturator procedure, it is speculative whether the length of the IF-PS distance may be predicted this way.

It should be also considered that due to study location all women were Caucasians, therefore, any variability related to ethnicity or race, which have significant implications for pelvic anatomy could not be evaluated.

In summary, the interobturator foramina line-pubic symphysis distance varies considerably in the general population of women. This observation suggests that the bony pelvis architecture may potentially affect the position of transobturator tape.

\section{Conflict of interest None.}

Open Access This article is distributed under the terms of the Creative Commons Attribution Noncommercial License which permits any noncommercial use, distribution, and reproduction in any medium, provided the original author(s) and source are credited.

\section{References}

1. Chen H-Y, Yeh L-S, Chang W-C, Ho M (2007) Analysis of risk factors associated with surgical failure of inside-out transobturator vaginal tape for treating urodynamic stress incontinence. Int Urogynecol J 18:443-447

2. Paick J-P, Cho MC, S-J Oh, Kim SW, Ku JH (2007) Factors influencing the outcome of mid urethral sling procedures for female urinary incontinence. J Urol 178:985-989

3. Barber MD, Kleeman S, Karram MM et al (2008) Rising $k$ factors associated with failure 1 year after retropubic or transobturator midurethral slings. Am J Obstet Gynecol 199(666):e1-e7

4. Rechberger T, Futyma K, Jankiewicz K, Adamiak A, Skorupski P (2009) The clinical effectiveness of retropubic (IVS-02) and transobturator (IVS-04) midurethral slings: randomized trial. Eur Urol 56:24-30

5. Kociszewski J, Rautenberg O, Perucchini D et al (2008) Tape functionality: sonographic tape characteristics and outcome after TVT incontinence surgery. Neurourol Urodynam 27:485-490

6. Yang JM, Yang SH, Huang WC (2009) Correlation of morphological alterations and functional impairment of the tension-free vaginal tape obturator procedure. J Urol 181:211-218

7. Petros P, Ulmsten U (1990) An integral theory of female urinary incontinence. Experimental and clinical considerations. Acta Obstet Gynecol Scand 69(suppl):153

8. Ng CC, Lee C, Han WH (2005) Use of three-dimensional ultrasound scan to assess the clinical importance of midurethral placement of the tension-free vaginal tape (TVT) for treatment of incontinence. Int Urogynecol J Pelvic Floor Dysfunct $16: 220-225$ 
9. Dietz HP, Mouritsen L, Ellis G, Wilson PD (2004) How important is TVT location? Acta Obstet Gynecol Scand 83:904-908

10. Lo T-S, Horng S-G, Liang C-C, Lee SJ, Soong YK (2004) Ultrasound assessment of mid-urethra tape at three-year followup after tension-free vaginal tape procedure. Urology 63:671675

11. Stankiewicz A, Wieczorek AP, Wozniak MM et al (2008) Comparison of accuracy of functional measurements of the urethra in transperineal vs. endovaginal ultrasound in incontinent women. Pelviperineology 27:145-147
12. Wang F, Song Y, Huang H (2009) Which placement of the tension-free vaginal tape is more important for urinary continence: midurethral position or bladder neck? Consideration from a case report. Int Urogynecol J Pelvic Floor Dysfunct 20:1277-1279

13. Handa VL, Lockhart ME, Kenton KS et al (2009) Magnetic resonance assessment of pelvic anatomy and pelvic floor disorders after childbirth. Int Urogynecol J Pelvic Floor Dysfunct 20:133-139

14. Stav K, Alcalay M, Peleg S, Lindner A, Gayer G, Hershkovitz I (2007) Pelvis architecture and urinary incontinence in women. Eur Urol 52:239-244 